\title{
PENGARUH KUALITAS LAYANAN, KEPUASAN, KEPERCAYAAN DAN KOMITMEN TERHADAP MINAT BERKUNJUNG KEMBALI PADA INDUSTRI KECANTIKAN
}

\author{
Margaretha Pink Berlianto
}

\author{
Program Manajemen, Fakultas Ekonomi, Universitas Pelita Harapan, Karawaci \\ margaretha.berlianto@uph.edu
}

\begin{abstract}
ABSTRAK
Penelitian ini bertujuan untuk menganalisis pengaruh kualitas layanan terhadap kepuasan, dan hubungan kepuasan, kepercayaan, dan komitmen terhadap revisit intention pada industri salon. Terdapat 5 hipotesis yang diuji pada penelitian ini. Jumlah sampel yang layak dan dapat digunakan sebanyak 185, dengan melakukan penyebaran kuisioner terhadap pelanggan salon X di Jakarta. Metode analisis data dengan menggunakan PLS-SEM. Teknik pengambilan sampel dengan menggunakan purposive sampling method. Hasil dari penelitian ini adalah kualitas layanan berpengaruh positif terhadap kepuasan, kepuasan berpengaruh positif terhadap kepercayaan dan revisit intention, kepercayaan berpengaruh positif terhadap komitmen dan komitmen berpengaruh positif terhadap revisit intention. Implikasi dari penelitian ini adalah pelaku bisnis salon perlu memperhatikan aspek-aspek seperti menggunakan peralatan up-to-date, memperhatikan penampilan karyawan, menyediakan ruangan salon yang menarik secara visual, dapat diandalkan, memiliki daya tanggap yang baik, memberikan jaminan transaksi yang baik, pengetahuan karyawan yang baik mengenai produk yang dijualnya, karyawan yang sopan dan memiliki empati. Juga harus menciptakan kepuasan, kepercayaan dan komitmen pelanggannya agar mendorong revisit intention.
\end{abstract}

\section{Kata kunci:}

Kualitas Layanan, Kepuasan, Kepercayaan, Komitmen, Revisit Intention

\begin{abstract}
This study aims to analyze the effect of service quality on satisfaction, and the relationship of satisfaction, trust, and commitment to the revisit intention in the salon industry. There are five hypotheses tested in this study. The samples size that feasible and can be used are 185, by distributing questionnaires to salon customers' X in Jakarta. Data analysis method in this study used PLS-SEM. The sampling technique used purposive sampling method. The results of this study are service quality has a positive effect on satisfaction, satisfaction has a positive effect on trust and revisit intention, trust has a positive commitment, and commitment has a positive effect on revisit intention. The implications of this research are salon business owner or manager need to pay attention to various aspects, such as using an up to date equipment, employee appearance, salon room have a good visually appealing, reliable, has good responsiveness, guarantees good transactions, a good product knowledge, employees are polite and have empathy. They also have to create satisfaction, trust, and commitment of their customers to encourage revisit intention.
\end{abstract}

Keywords:

Service Quality, Satisfaction, Trust, Commitment, Revisit Intention 
Pengaruh Kualitas Layanan, Kepuasan, Kepercayaan dan ... (Margaretha Pink Berlianto)

\section{PENDAHULUAN}

Saat ini, kesadaran masyarakat Indonesia terhadap kesehatan dan perawatan tubuh semakin meningkat. Kondisi ini mendorong pelaku bisnis di industri kecantikan untuk melakukan ekspansi, termasuk juga perusahaan kecantikan asing untuk masuk ke pasar Indonesia. Pertumbuhan di industri kecantikan pada tahun 2017 sebesar $10.6 \%$, di mana akan terus bertumbuh ke depannya (Dwiyanto, 2018). Salah satu industri kecantikan adalah industri salon. Menurut laporan Loreal Foundation, industri salon di Indonesia pada tahun 2015 menyumbang Rp 1,2 trilyun dalam perekonomian Indonesia. Nilai ini sangat besar sehingga membuat pelaku bisnis tertarik untuk masuk dan berinvestasi lebih banyak lagi pada industri ini (Yusmadi, 2015).

Membuka bisnis salon bukan persoalan mudah, dikarenakan membutuhkan modal, teknik dan alat sebagai fondasi utama dan juga cenderung beresiko untuk bertahan di tengah persaingan industri kecantikan. Selain itu pelaku bisnis juga perlu mengikuti perkembangan jaman agar dapat bertahan (Yusmadi, 2015). Untuk itu agar pelaku bisnis salon dapat bertahan dan memenangkan persaingan yang ketat dalam industri ini, mereka perlu mengetahui sejauh mana kualitas layanan yang mereka berikan telah sesuai dengan apa yang diharapkan pelanggannya dan sejauh mana kualitas layanan tersebut mempengaruhi kepuasan pelanggan sehingga pada akhirnya pelanggan mereka mau mengunjungi kembali atau mendapatkan perawatan kecantikan kembali dari salon tersebut. Terdapat perkembangan literatur mengenai kualitas layanan di berbagai produk dan industri, namun sepanjang pencarian literatur yang ada, sangat sedikit penelitian yang meneliti mengenai kualitas layanan kecantikan khususnya pada salon di Indonesia. Untuk itu, penelitian ini bertujuan untuk mengivestigasi kualitas layanan dari salah satu salon di Jakarta dan bagaimana pengaruhnya terhadap kepuasan pelanggan. Selain itu, penelitian ini juga bertujuan untuk menginvestigasi sejauh mana pengaruh kepuasan tersebut terhadap kepercayaan dan revisit intention, pengaruh kepercayaan terhadap komitmen dan pengaruh komitmen terhadap revisit intention.

\section{Rumusan Masalah}

Rumusan masalah dari penelitian ini adalah: 
1. Kualitas layanan berpengaruh positif terhadap kepuasan

2. Kepuasan berpengaruh positif terhadap kepercayaan

3. Kepercayaan berpengaruh positif terhadap komitmen

4. Kepuasan berpengaruh positif terhadap revisit intention

5. Komitmen berpengaruh positif terhadap revisit intention

\section{TINJAUAN TEORI DAN}

\section{PENGEMBANGAN HIPOTESIS}

\section{Service Quality}

Kualitas merupakan poros penggerak utama kepuasan (Han \& Ryu, 2007). Menurut Shang (2014), kualitas jasa merupakan indikator kunci dari kinerja pada evaluasi jasa tradisional. Kualitas layanan telah diidentifikasi sebagai agen yang dapat mempengaruhi secara langsung kepuasan pelanggan, perilaku pengulangan pembelian, dan jaminan profitabilitas organisasi dalam jangka panjang (Wilkins, Merrilees, \& Herington, 2007). Kualitas layanan didefinisikan sebagai persentase perbedaan antara harapan pelanggan tentang produk dan sifat pengalaman yang diperolehnya setelah menggunakan layanan atau mengkonsumsi produk (Parasuraman, Zithaml, \& Berry, 1988). Jika pelanggan menerima layanan yang melebihi harapannya, maka kualitas layanan tersebut sempurna.

Terdapat beberapa pendapat para ahli mengenai dimensi-dimensi dari kualitas layanan, seperti yang disampaikan oleh Parasuraman, Zithaml, \& Berry (1988) yang dikenal dengan SERVQUAL, SERVPERF yang diperkenalkan oleh Cronin \& Taylor (1992), HEDPERF (High Education Performance) yang diperkenalkan oleh Abdullah (2004) dan lainnya. Pada penelitian ini menggunakan Servqual. Servqual terdiri dari 5 dimensi yaitu tangibles, empati, jaminan, keandalan dan daya tanggap. Tangibles merupakan tampilan dari fasilitas fisik, peralatan, personel dan material komunikasi. Keandalan adalah kemampuan untuk melakukan layanan yang telah dijanjikan dengan andal dan akurat. Daya tanggap adalah kemauan untuk membantu pelanggan dan menyediakan layanan dengan cepat. Jaminan adalah pengetahuan atau kesopanan karyawan dan kemampuan mereka untuk menginspirasi kepercayaan dan keyakinan. Empati adalah kepedulian, perhatian individual 
Pengaruh Kualitas Layanan, Kepuasan, Kepercayaan dan ... (Margaretha Pink Berlianto)

yang disediakan oleh perusahaan kepada

pelanggannya (Parasuraman et al., 1988).

\section{Satisfaction}

Kepuasan merupakan faktor kunci dalam berkompetisi dengan pesaing dan mencapai keberhasilan di pasar (Anderson \& Srinivasan, 2003). Kepuasan didefinisikan sebagai evaluasi paska pembelian konsumen dan respon afektif pelanggan terhadap pengalaman menggunakan produk dan layanan (Oliver, 1980). Sedangkan Senić \& Marinković (2013) mendefinisikan kepuasan sebagai perasaan yang timbul pada pelanggan setelah menyelesaikan pembelian atau pada fase setelah akuisisi layanan.

Penelitian terdahulu menemukan bahwa kualitas layanan berpengaruh positif terhadap kepuasan, seperti Zeglat, Shrafat, \& Al-smadi (2016) pada kualitas layanan pembelajaran elektronik di Jordania, Haryono, Suharyono, Fauzi, \& Suyadi (2015) pada pelanggan penerbangan full-service domestic di Yogjakarta dan Prameka, Do, \& Rofiq (2016) pada industri perhotelan. Berdasarkan uraian di atas, maka:

H1: Kualitas layanan berpengaruh positif terhadap kepuasan

\section{Trust}

Kepercayaan merupakan kunci penting untuk memelihara kelanjutan hubungan antara pelanggan dan penyedia jasa (Han \& Hyun, 2013) dan memainkan peranan penting dalam membentuk hubungan lestari dengan pelanggan (Lee, Moon, Kim, \& Yi, 2015). Kepercayaan merupakan sesuatu yang rumit dan subjektif karena lebih didasarkan pada keyakinan konsumen daripada fakta-fakta keras (Yannopoulou, Koronis, \& Elliott, 2011). Kepercayaan didefinisikan sebagai keyakinan bahwa suatu pihak dapat diandalkan dan bertanggungjawab penuh dalam hubungan kepercayaan (Barnes, Leonidou, Siu, \& Leonidou, 2010). Pada penelitian ini, kepercayaan yang dimaksudkan adalah keyakinan pelanggan terhadap layanan salon $\mathrm{X}$.

Menurut Athanassopoulos, Gounaris, \& Stathakopoulos (2001), kepuasan berkaitan dengan word of mouth positif dan meningkatkan tingkat kepercayaan pelanggan. Beberapa penelitian terdahulu menemukan bahwa kepuasan berpengaruh terhadap kepercayaan, seperti Lee, Yim, Jones, \& Kim (2016) pada performing art di Korea Selatan, Han \& Hyun 
(2015) pada industri wisata medis di Korea Selatan, Fang et al. (2014) pada pembelian online, dan Prameka et al., (2016) pada industri perhotelan di Malang. Akan tetapi hasil penelitian Haryono et al. (2015) pada industri maskapai penerbangan menemukan bahwa kepuasan tidak berpengaruh terhadap kepercayaan. Berdasarkan uraian di atas, maka dibangunlah hipotesis berikut:

H2: Kepuasan berpengaruh positif terhadap kepercayaan

\section{Commitment}

Komitmen merupakan suatu permintaan yang berkelanjutan untuk memelihara hubungan yang penting (Li \& Chang, 2016). Menurut Erciş, Ünal, Candan, \& Yildırım (2012), komitmen mengacu pada keinginan abadi untuk melanjutkan hubungan terhadap sebuah merek. Kepercayaan pelanggan memainkan peranan penting dalam komitmen pelanggan (Prameka et al., 2016). Komitmen didefinisikan sebagai kebutuhan berkelanjutan untuk mempertahankan hubungan (Moorman, Zaltman, \& Deshpande, 1992) Pada penelitian ini, komitmen mengacu pada komitmen atau sikap pelanggan untuk berhubungan dengan industri kecantikan tersebut. Li \& Chang (2016) menyatakan bahwa kepercayaan berpengaruh terhadap komitmen. Pernyataan ini didukung oleh penelitian yang dilakukan oleh Riorini (2016) pada industri restoran waralaba lokal, Mlaker Kač, Gorenak, \& Potočan (2015) di Slovenia, Chou \& Chen (2018) pada industri jasa di Taiwan, Ferro, Padin, Svensson, \& Payan (2016) di Spanyol, dan Mukherjee \& Nath (2007) di Inggris. Berdasarkan uraian di atas, maka:

H3: Kepercayaan berpengaruh positif terhadap Komitmen

\section{Revisit Intention}

Behavioral intention adalah konsekuensi dari kepercayaan dan komitmen (Mukherjee \& Nath, 2007). Terdapat berbagai wujud dari behavioral intention, seperti repurchase intention, revisit intention maupun intention to continued use. Konsep revisit intention pelanggan merupakan turunan dari behavioral intention (Wu, Cheng, \& Hong, 2017). Penelitian ini lebih berfokus pada revisit intention. Revisit intention adalah kemungkinan pelanggan untuk 
mengunjungi kembali atau melakukan pembelian kembali produk atau layanan yang pernah digunakan atau diterima oleh pelanggan (Ajzen, 2005). Pada penelitian ini, revisit intention mengacu pada ketertarikan pelanggan untuk mengunjungi atau membeli kembali layanan yang ditawarkan oleh salon kecantikan tersebut.

Beberapa penelitian terdahulu menemukan bahwa kepuasan berpengaruh positif terhadap revisit intention, seperti penelitian tom Dieck, Jung, Kim, \& Moon (2017) pada industri perhotelan, penelitian Wu, Cheng, \& Hong (2017) terhadap pelanggan kebun binatang di Beijing, dan Susanto, Chang, \& Ha (2016). Akan tetapi, hasil berbeda ditemukan pada penelitian Haryono et al. (2015) industri maskapai penerbangan dan penelitian Chen \& Chen (2017) pada bidang asuransi keuangan di Taiwan yang menemukan bahwa kepuasan tidak berpengaruh terhadap revisit intention.

Selain kepuasan berpengaruh terhadap revisit intention, komitmen juga ditemukan memiliki pengaruh terhadap revisit intention, seperti pada penelitian Chou \& Chen (2018) pada 5 penyedia layanan jasa di Taiwan menemukan bahwa komitmen berpengaruh terhadap revisit intention, penelitian Mykletun \& Himanen (2016) di Norwegia, penelitian Elbeltagi \& Agag (2016) pada pembeli online di Mesir, dan penelitian Chen \& Chen (2017) di Taiwan. Berdasarkan uraian di atas, maka:

\section{H4: Kepuasan berpengaruh positif} terhadap revisit intention

H5: Komitmen berpengaruh positif terhadap revisit intention

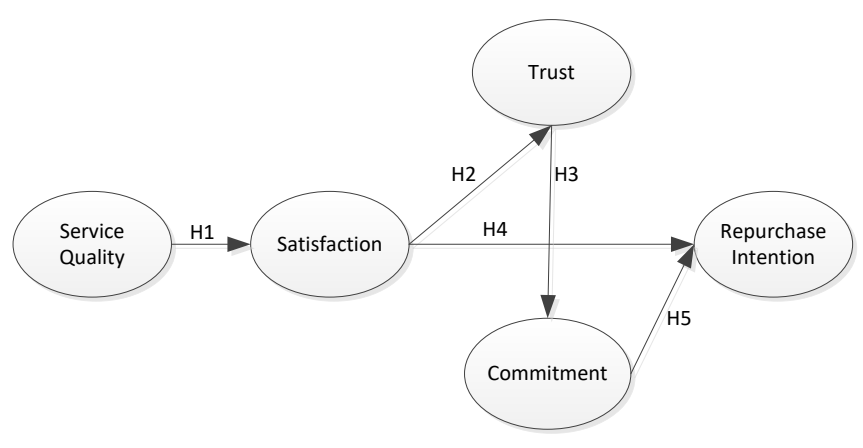

Gambar 1. Kerangka Konseptual

Sumber: Dikembangkan untuk penelitian ini (2018)

\section{METODE RISET}

Populasi dari penelitian ini adalah pelanggan salon $\mathrm{X}$ di Jakarta. Jumlah sampel yang diambil pada penelitian ini adalah 205 responden. Dengan perhitungan 41 indikator yang ada dikali 5. Teknik pengambilan sampel adalah purposive sampling dengan kriteria pelanggan salon $\mathrm{X}$ di Jakarta. Sumber data yang 
digunakan adalah data primer dengan penyebaran kuisioner. Terdapat 5 variabel pada penelitian ini, yaitu kualitas layanan, kepuasan, kepercayaan, komitmen dan revisit intention. Kualitas layanan terdiri dari 22 indikator yang diadopsi dari Parasuraman, Zithaml, \& Berry (1988). Kepuasan terdiri dari 7 indikator yang diadopsi dari Noyan \& Simsek (2014). Kepercayaan terdiri dari 4 indikator yang diadopsi dari Colesca (2009). Komitmen terdiri dari 4 indikator yang diadopsi dari Hennig-Thurau, Gwinner, \& Gremler (2002). Sementara revisit intention terdiri dari 4 indikator yang diadopsi dari Chow, Ong, Tham, \& Wong (2013). Metode analisis data yang digunakan adalah Partial Least Square Strutural Equation Modeling technique (PLSSEM).

\section{HASIL PENELITIAN DAN PEMBAHASAN}

Dari 205 kuisioner yang disebarkan, terdapat 184 kuisioner yang dapat digunakan pada penelitian ini. Profil responden dapat dilihat pada tabel 1 .

\section{Pengujian Validitas dan Reliabilitas}

Untuk menentukan apakah indikator yang digunakan valid, maka dilakukan evaluasi outer model. Evaluasi outer model dilakukan dengan melihat nilai outer loading di atas 0.6 dan nilai Average Variance Extracted di atas 0.5 dan dengan pengujian validitas diskriminan. Selanjutnya dilakukan pengujian reliabilitas masing-masing konstruk dengan melihat nilai Composite Reliability diatas 0.7. Terdapat beberapa indikator yang dihapus karena memiliki nilai outer loading di bawah 0.6 dan ada beberapa indikator yang dihapus agar dapat mencapai nilai AVE di atas 0.5. Tabel 2 menunjukkan hasil dari perhitungan outer model, di mana indikatorindikator yang ada telah valid dan konstruk yang ada telah reliabel.

\section{Pengujian Validitas dan Reliabilitas}

Untuk menentukan apakah indikator yang digunakan valid, maka dilakukan evaluasi outer model. Evaluasi outer model dilakukan dengan melihat nilai outer loading di atas 0.6 dan nilai Average Variance Extracted di atas 0.5 dan dengan pengujian validitas diskriminan. Selanjutnya dilakukan pengujian reliabilitas masing-masing konstruk dengan melihat nilai Composite Reliability di atas 0.7. Terdapat beberapa indikator yang dihapus karena memiliki 
Pengaruh Kualitas Layanan, Kepuasan, Kepercayaan dan ... (Margaretha Pink Berlianto)

Tabel 1.

Profil Responden

\begin{tabular}{lcc}
\hline \multicolumn{1}{c}{ Statements } & Total & Percentage (\%) \\
\hline Jenis Kelamin & 32 & 17.40 \\
Pria & 152 & 82.60 \\
Wanita & & 0 \\
Usia & 0 & 25.5 \\
117 & 47 & 74.5 \\
$>31$ & 137 & 0 \\
Frekuensi ke Salon X dalam waktu 6 bulan terakhir & & 4,4 \\
$1 X$ & 0 & 48,9 \\
$2 X$ & 2 & 46.7 \\
$3 X$ & 90 & 62.5 \\
$>3 X$ & 86 & 16.3 \\
Pekerjaan & & 21.2 \\
Pelajar & 115 & \\
Karyawan & 30 & \\
Lainnya & 39 & \\
\hline
\end{tabular}

Sumber: hasil diolah SPSS (2018)

Tabel 2.

Pengukuran Validitas and Reliabilitas

\begin{tabular}{|c|c|}
\hline Kontruks \& item & Outer Loading \\
\hline \multicolumn{2}{|l|}{ Service Quality $(C R=0,923, A V E=0,500)$} \\
\hline Saya dapat mempercayai karyawan Salon X & 0,780 \\
\hline Saya merasa aman bertransaksi dengan karyawan Salon X.. & 0,712 \\
\hline Karyawan Salon X sopan. & 0,716 \\
\hline Salon X memberikan perhatian individu. & 0,688 \\
\hline Karyawan Salon X memberikan perhatian secara personil. & 0,714 \\
\hline Karyawan Salon X selalu bersedia membantu pelanggan. & 0,721 \\
\hline Karyawan Salon X segera merespon permintaan pelanggan. & 0,660 \\
\hline Ketika Salon X menjanjikan sesuatu dengan waktu tertentu, mereka menepatinya. & 0,682 \\
\hline Ketika pelanggan menghadapi masalah, Salon X menunjukkan sikap yang simpatik. & 0,773 \\
\hline Ketika pelanggan menghadapi masalah, Salon X menunjukkan sikap meyakinkan. & 0,708 \\
\hline Salon X memiliki peralatan terkini & 0,645 \\
\hline Karyawan Salon X berpenampilan menarik. & 0,678 \\
\hline \multicolumn{2}{|l|}{ Kepuasan $(C R=0,865, A V E=0,518)$} \\
\hline $\begin{array}{l}\text { Saya pikir, dengan menggunakan layanan kecantikan dari Salon X adalah keputusan yang } \\
\text { baik. }\end{array}$ & 0,678 \\
\hline Salon X mengambil Kepuasan pelanggan adalah tujuan dari Salon X. & 0,626 \\
\hline Saya puas dengan pelayanan Salon X. & 0,690 \\
\hline Secara umum saya puas dengan Salon $\mathrm{X}$. & 0,802 \\
\hline Saya puas dengan harga yang diberikan oleh Salon X. & 0,722 \\
\hline Saya sangat puas dengan Salon $\mathrm{X}$. & 0,786 \\
\hline \multicolumn{2}{|l|}{ Kepercayaan $(C R=0,751, A V E=0,621)$} \\
\hline Saya percaya bahwa Salon X tidak akan merugikan saya & 0,601 \\
\hline Saya percaya dengan Salon X. & 0,979 \\
\hline \multicolumn{2}{|l|}{ Komitmen $(C R=0,825, A V E=0,703)$} \\
\hline \multicolumn{2}{|l|}{ Kedai kopi X nyaman untuk sendiri. } \\
\hline Hubungan saya dengan Salon X adalah sangat penting. & 0.892 \\
\hline \multicolumn{2}{|l|}{ Revisit intention $(C R=0,779, A V E=0,639)$} \\
\hline Saya akan mengatakan hal yang positif tentang Salon X kepada orang lain & 0.846 \\
\hline $\begin{array}{l}\text { Saya mengganggap bahwa melakukan perawatan rambut di Salon X adalah salah satu } \\
\text { pilihan di daftar saya. }\end{array}$ & 0.750 \\
\hline
\end{tabular}


Notes: $C R=$ Composite Reliability; $A V E=$ average variance extracted.

Sumber: Hasil pengolahan data PLS (2018)

Tabel 3.

Validitas Diskriminan

\begin{tabular}{lccccc}
\hline & Kepuasan & Revisit Intention & $\begin{array}{l}\text { Kualitas } \\
\text { Layanan }\end{array}$ & Komitmen & Kepercayaan \\
\hline Kepuasan & $\mathbf{0 , 7 2 0}$ & & & & \\
Revisit Intention & 0,444 & $\mathbf{0 , 7 9 9}$ & & & \\
Kualitas Layanan & 0,299 & 0,306 & $\mathbf{0 , 7 0 7}$ & $\mathbf{0 , 8 3 8}$ & \\
Komitmen & 0,390 & 0,568 & 0,357 & 0,455 & $\mathbf{0 , 7 8 8}$ \\
Kepercayaan & 0,243 & 0,396 & 0,202 &
\end{tabular}

Sumber: Hasil pengolahan data PLS (2018)

Tabel 4.

Hasil Uji Hipotesis

\begin{tabular}{clcc}
\hline Hipotesis & \multicolumn{1}{c}{ Jalur } & $\mathrm{P}$ value & Hasil \\
\hline $\mathrm{H}_{1}$ & Kualitas Layanan $\rightarrow$ Kepuasan & 0,000 & Signifikan \\
$\mathrm{H}_{2}$ & Kepuasan $\rightarrow$ Kepercayaan & 0,000 & Signifikan \\
$\mathrm{H}_{3}$ & Kepercayaan $\rightarrow$ Komitmen & 0,000 & Signifikan \\
$\mathrm{H}_{4}$ & Kepuasan $\rightarrow$ revisit intention & 0,000 & Signifikan \\
$\mathrm{H}_{5}$ & Komitmen $\rightarrow$ revisit Intention & 0,000 & Signifikan \\
\hline
\end{tabular}

Sumber: Hasil pengolahan data dengan PLS (2018)

nilai outer loading di bawah 0.6 dan ada beberapa indikator yang dihapus agar dapat mencapai nilai AVE di atas 0.5. Tabel 2 menunjukkan hasil dari perhitungan outer model, di mana indikatorindikator yang ada telah valid dan konstruk yang ada telah reliabel.

Tabel 3 menunjukkan hasil dari uji validitas deskriminan, di mana hasil uji validitas diskriminan pada penelitian ini memiliki nilai validitas deskriminan yang baik, dikarenakan nilai cross loading factor dari konstruk yang dituju lebih besar dibandingkan dengan nilai cross loading factor pada konstruk yang lain.
Tabel 4 menunjukkan hasil pengujian hipotesis di mana kelima hipotesis yang ada adalah signifikan karena memiliki $p$ value lebih kecil 0,05.

\section{Diskusi}

Hasil penelitian ini menunjukkan bahwa kualitas layanan berpengaruh positif terhadap kepuasan. Hasil ini mendukung penelitian sebelumnya (Haryono et al., 2015; Prameka et al., 2016; Zeglat et al., 2016). Penelitian ini mengkonfirmasi penelitian Parasuraman et al. (1988) mengenai dimensi-dimensi Servqual, yaitu tangibles, reliability (keandalan), 
Pengaruh Kualitas Layanan, Kepuasan, Kepercayaan dan ... (Margaretha Pink Berlianto)

responsiveness (daya tanggap), assurance

(jaminan) dan empati. Dengan kata lain, tangibles, keandalan, daya tanggap, jaminan dan empati merupakan faktor penting dalam membentuk kepuasan pelanggan pada industri salon kecantikan. Hipotesis 2 menyatakan bahwa kepuasan berpengaruh positif terhadap kepercayaan. Hasil uji hipotesis menunjukkan bahwa hipotesis ini diterima. Hasil penelitian ini mendukung hasil dari penelitian sebelumnya, yaitu Lee et al. (2016) pada industri kesenian di Korea Selatan, Han \& Hyun (2015) pada industri wisata medis di Seoul dan Prameka et al. (2016) pada industri perhotelan di Malang. Selanjutnya ditemukan bahwa kepercayaan berpengaruh positif terhadap komitmen (H3), di mana hasil ini didukung oleh penelitian sebelumnya (Chou \& Chen, 2018; Ferro et al., 2016; Li \& Chang, 2016; Mlaker Kač et al., 2015; Riorini, 2016). Kepuasan ditemukan berpengaruh positif terhadap revisit intention (H4). Hasil ini didukung oleh penelitian tom Dieck et al. (2017) pada industri perhotelan, penelitian $\mathrm{Wu}$ et al. (2017) di Beijing, dan Susanto et al. (2016). Dari hasil profil responden dapat dilihat bahwa lebih dari $50 \%$ pelanggan telah melakukan kunjungan kembali ke salon $\mathrm{X}$ dalam kurun waktu 6 bulan terakhir kedatangannya. Bahkan ada yang lebih dari 4 kali $(46,7 \%)$ kembali berkunjug ke salon $\mathrm{X}$ selama kurun waktu 6 bulan terakhir. Dapat dikatakan bahwa tingkat revisit intention pelanggan salon $\mathrm{X}$ sangat baik. Komitmen berpengaruh terhadap revisit intention. Hasil penelitian ini mendukung penelitian sebelumnya, yaitu Chou \& Chen (2018) pada industri penyedia layanan di Taiwan, Mykletun \& Himanen (2016) di Norwegia dan Elbeltagi \& Agag (2016) di Mesir.

\section{KESIMPULAN DAN SARAN}

\section{Kesimpulan}

Berdasarkan hasil analisis dan pembahasan, maka kesimpulan dari penelitian ini adalah:

1. Kualitas layanan berpengaruh positif terhadap kepuasan. Hal ini menunjukkan bahwa indikator-indikator dan dimensi yang ada (tangibles, keandalan, daya tanggap, jaminan, dan empati) pembentuk kualitas layanan dapat membantu membentuk kepuasan pelanggan

2. Kepuasan berpengaruh positif terhadap kepercayaan. Hal ini menunjukkan bahwa 
indikator-indikator pembentuk kepuasan

dapat membantu membentuk kepercayaan.

3. Kepercayaan berpengaruh positif terhadap komitmen. Hal ini menunjukkan bahwa indikator-indikator kepercayaan dapat membantu membentuk komitmen pelanggan.

4. Kepuasan berpengaruh positif terhadap revisit intention. Hal ini menunjukkan bahwa indikator-indikator kepuasan yang ada dapat membentuk revisit intention pelanggan.

5. Komitmen berpengaruh positif terhadap revisit intention. Hal ini menunjukkan bahwa indikator-indikator komitmen yang ada dapat membentuk revisit intention pelanggan.

\section{Implikasi}

Penelitian ini memberikan implikasi secara teoritis dan manajerial. Implikasi teoritis dari penelitian ini adalah memberikan tambahan literatur mengenai pengaruh positif kualitas layanan terhadap kepuasan, pengaruh positif kepuasan terhadap kepercayaan dan revisit intention, pengaruh positif kepercayaan terhadap komitmen dan komitmen berpengaruh positif terhadap revisit intention, khususnya di industri salon kecantikan di Jakarta. Selain itu juga memberikan tambahan literatur bahwa dimensi dari kualitas jasa yang diperkenalkan oleh (Parasuraman et al., 1988) dapat digunakan juga pada industri salon kecantikan.

Implikasi manajerial dari penelitian ini adalah bahwa kualitas layanan merupakan faktor penting yang mempengaruhi kepuasan pelanggan. Untuk itu pelaku bisnis salon perlu memperhatikan aspek tangibles seperti memiliki peralatan salon yang up to date, design ruang salon yang menarik secara visual, dan juga memperhatikan kerapian dari penampilan karyawannya. Selain aspek tangible, mereka juga perlu memperhatikan aspek keandalan, yaitu menepati janji yang telah diucapkan, menunjukkan sikap yang simpatik kepada pelanggan ketika pelanggan menghadapi suatu masalah, dan dapat diandalkan. Selanjutnya pelaku bisnis salon juga perlu memperhatikan aspek daya tanggap, seperti memberikan informasi mengenai kapan layanan akan diberikan ketika mereka harus mengantri karena salon sedang ramai, memberikan layanan yang tepat waktu, pegawai salon tidak korupsi waktu layanan, dan karyawan salon merespon permintaan pelanggan dengan segera. Pelaku bisnis salon juga perlu memperhatikan aspek 


\section{Pengaruh Kualitas Layanan, Kepuasan, Kepercayaan dan ... (Margaretha Pink Berlianto)}

assurance, seperti karyawan yang dapat dipercaya oleh pelanggan, memiliki pengetahuan tentang produk yang dijual dan keterampilan profesi yang baik, memberikan keamanan dalam bertransaksi, bersikap sopan dan lainnya. Aspek terakhir adalah empati. Pelaku bisnis salon diharapkan dapat memberikan perhatian secara personil kepada pelanggannya dan juga mengetahui kebutuhan pelanggan. Untuk dapat mengetahui apa yang menjadi kebutuhan pelanggan, karyawan dapat memulai percakapan dengan pelanggannya sehingga mengetahui kebutuhan mereka. Implikasi manajerial yang kedua adalah kepuasan yang merupakan faktor penting yang mempengaruhi kepercayaan dan revisit intention. Meningkatkan kepuasan pelanggan dapat dilakukan melalui memberikan layanan yang baik, harga yang wajar, dan memberikan perhatian kepada pelanggannya. Implikasi yang ketiga adalah kepercayaan yang merupakan faktor penting yang mempengaruhi komitmen. Oleh karena itu, sangatlah penting bagi pelaku bisnis salon meningkatkan kepercayaan pelanggannya. Kepercayaan pelanggan dapat dibentuk melalui penepatan janji, menjual produk yang berkualitas, tidak melakukan gosip dan lainnya. Implikasi manajerial yang terakhir adalah komitmen yang merupakan faktor penting yang mempengaruhi revisit intention. Untuk itu, pelaku bisnis salon perlu meningkatkan komitmen pelanggannya melalui kepercayaan, kepuasan, memberikan layanan yang baik dan berbeda dengan pesaing, dan lainnya.

\section{Keterbatasan dan Saran Penelitian}

Keterbatasan penelitian ini adalah hanya menguji 5 dimensi dari kualitas layanan dari Parasuraman et al. (1988) yaitu tangible, daya tanggap, keandalan, jaminan dan empati. Penelitian selanjutnya dapat mencoba menggunakan dimensi lain dari kualitas layanan yang diperkenalkan oleh Cronin \& Taylor (1992) atau lainnya.

Keterbatasan yang kedia adalah penelitian ini hanya dilakukan pada salon $\mathrm{X}$ dan $\mathrm{Y}$. penelitian selanjutnya dapat mencoba menguji model yang ada pada salon lain atau pada lokasi yang berbeda. Keterbatasan yang ketiga adalah jumlah sampel yang ada walaupun sudah cukup memadai untuk dilakukan pengujian, namun alangkah baiknya jika ditambah jumlahnya untuk penelitian selanjutnya. 


\section{DAFTAR PUSTAKA}

Abdullah, F. (2004). Managing service quality in higher education sector: a new perspective throygh development of a comprehensice measuring scale. In Proceedings of the Global Conference on Excellence in Education and Training: Educational Excellende through Creativity, Innovation \& Enterprise. Singapore.

Ajzen, I. (2005). Attitudes, Personality, and Behavior (2nd ed.). Berkshire, UK: Open University Press. Retrieved from https://books.google.co.id/books?hl=en\&lr=\&id=dmJ9EGEy0ZYC\&oi=fnd\&pg=PP1\&dq=Ajzen,+I .$+(2005) .+$ Attitudes, + personality, + and+behavior+(2nd+ed.).+Berkshire, + UK:+Open+University $+\operatorname{Pr}$ ess\&ots $=\mathrm{ECMNPjJY} 4 \mathrm{y} \&$ sig $=\mathrm{wM}-$

TRZQ0VhBK01GM41_M3fiCi84\&redir_esc=y\#v=onepage\&q\&f=fal

Anderson, R. E., \& Srinivasan, S. S. (2003). E-Satisfaction and E-Loyalty: A Contingency Framework. Psychology and Marketing, 20(2), 123-138.

Athanassopoulos, A., Gounaris, S., \& Stathakopoulos, V. (2001). Behavioural responses to customer satisfaction: an empirical study. European Journal of Marketing, 35(5/6), 687-707. http://doi.org/10.1108/03090560110388169

Barnes, B. R., Leonidou, L. C., Siu, N. Y. ., \& Leonidou, C. N. (2010). Opportunism as the Inhibiting Trigger for Developing Long-Term-Oriented Western Exporter-Hong Kong Importer Relationships. Journal of International Marketing, 18(2), 35-63. http://doi.org/10.1509/jimk.18.2.35

Chen, C.-C. V., \& Chen, C.-J. (2017). The role of customer participation for enhancing repurchase intention. Management Decision, 55(3), 547-562. http://doi.org/10.1108/MD-06-2016-0380

Chou, S., \& Chen, C. (2018). The influences of relational benefits on repurchase intention in service contexts : the roles of gratitude, trust and commitment. Journal of Business and Industrial Marketing, 33(5), 680-692. http://doi.org/10.1108/JBIM-08-2017-0187

Chow, K. Y., Ong, D. C. S., Tham, W. L., \& Wong, Y. K. (2013). Factors Influencing Dinning Experience on Customer Satisfaction and Revisit Intention Among Undergraduates Towards Fast Food Restaurants. Universiti Tunku Abdul Rahman.

Colesca, S. E. (2009). Increasing E-Trust: A Solution To Minimize Risk In E-Government Adoption. Journal of Applied Quantitative Methods, 4(1), 1-16.

Cronin, J. J., \& Taylor, S. . (1992). Measuring service quality: reexamination and extension. Journal of Marketing, 56, 55-68.

Dwiyanto, A. (2018). Industri kecantikan pede bisnis kian bertumbuh, pebisnis gencar ekspansi. Retrieved March 2, 2018, from https://industri.kontan.co.id/news/industri-kecantikan-pede-bisniskian-bertumbuh-pebisnis-gencar-ekspansi

Elbeltagi, I., \& Agag, G. (2016). E-retailing ethics and its impact on customer satisfaction and repurchase intention: A cultural and commitment-trust theory perspective. Journal of Internet Research, 26(1), $288-310$. 
Pengaruh Kualitas Layanan, Kepuasan, Kepercayaan dan ... (Margaretha Pink Berlianto)

Erciş, A., Ünal, S., Candan, F. B., \& Yıldırım, H. (2012). The Effect of Brand Satisfaction, Trust and Brand Commitment on Loyalty and Repurchase Intentions. Procedia - Social and Behavioral Sciences, 58, 1395-1404. http://doi.org/10.1016/j.sbspro.2012.09.1124

Fang, Y., Qureshi, I., Sun, H., McCole, P., Ramsey, E., \& Lim, K. . (2014). Trust, Satisfaction, and Online Repurchase Intention: The Moderating Role of Perceived Effectiveness of e-commerce Institutional Mechanisms. MIS Quarterly, 38(2), 407-427.

Ferro, C., Padin, C., Svensson, G., \& Payan, J. (2016). Trust and commitment as mediators between economic and non-economic satisfaction in manufacturer-supplier relationships. Journal of Business \& Industrial Marketing, 31(1), 13-23. Retrieved from http://www.emeraldinsight.com/doi/10.1108/JBIM-07-2013-0154

Han, H., \& Hyun, S. S. (2013). Image Congruence and Relationship Quality in Predicting Switching Intention: Conspicuousness of Product Use as a Moderator Variable. Journal of Hospitality and Tourism Research, 37(3), 303-329. http://doi.org/10.1177/1096348012436381

Han, H., \& Hyun, S. S. (2015). Customer retention in the medical tourism industry: Impact of quality, satisfaction, trust, and price reasonableness. Tourism Management, 46(October), 20-29. http://doi.org/10.1016/j.tourman.2014.06.003

Han, H., \& Ryu, K. (2007). Moderating Role of Personal Characteristics in Forming Restaurant Customers' Behavioral Intentions: An Upscale Restaurant Setting. Journal of Hospitality \& Leisure Marketing, 15(4), 25-54. http://doi.org/10.1300/J150v15n04_03

Haryono, S., Suharyono, Fauzi, A., \& Suyadi, I. (2015). The Effects of Service Quality on Customer Satisfac tion, Customer Delight, Trust, Repurchase Intention, and Word of Mouth. European Journal of Business and Management , 17(12), 36-48.

Hennig-Thurau, T., Gwinner, K. P., \& Gremler, D. D. (2002). Understanding Relationship Marketing Outcomes: An Integration of Relational Benefits and Relationship Quality. Journal of Service Research, 4(3), 230-247.

Lee, D., Moon, J., Kim, Y. J., \& Yi, M. Y. (2015). Antecedents and consequences of mobile phone usability: Linking simplicity and interactivity to satisfaction, trust, and brand loyalty. Information and Management, 52(3), 295-304. http://doi.org/10.1016/j.im.2014.12.001

Lee, Y.-G., Yim, B. H., Jones, C. W., \& Kim, B.-G. (2016). The extended marketing mix in the context of dance as a performing art. Social Behavior and Personality, 44(6), 1043-1056. http://doi.org/10.2224/sbp.2016.44.6.1043

Li, C.-H., \& Chang, C.-M. (2016). The influence of trust and perceived playfulness on the relationship commitment of hospitality online social network-moderating effects of gender. International Journal of Contemporary Hospitality Management, 28(5), 924-944. http://doi.org/10.1108/IJCHM05-2014-0227

Mlaker Kač, S., Gorenak, I., \& Potočan, V. (2015). Influence of Relationship Commitment and Trust on Collaborative Behaviour in Supply Chains. PROMET - Traffic\&Transportation, 27(1). http://doi.org/10.7307/ptt.v27i1.1575

Moorman, C., Zaltman, G., \& Deshpande, R. (1992). Relationships Between Providers and Users of 
Market Research: The Dynamics of Trust Within and Between Organizations. Journal of Marketing Research (JMR), 29(3), 314-328. Retrieved from

http://search.ebscohost.com/login.aspx?direct=true \&db=bth\&AN=9602160655\&site=ehost-live

Mukherjee, A., \& Nath, P. (2007). Role of Electronic Trust in Online Retailing: A Re-Examination of The commitment-trust theory. European Journal of Marketing (Vol. 41).

http://doi.org/10.1108/03090560710773390

Mykletun, R. J., \& Himanen, K. (2016). Volunteers at biking race events Antecedents of commitment and intention to remain volunteering at future events. Sport, Business and Management: An International Journal, 6(3), 2016.

Noyan, F., \& Simsek, G. G. (2014). The Antecedents of Customer Loyalty. Procedia - Social and Behavioral Sciences, 109, 1220-1224. http://doi.org/10.1177/109467059914007

Oliver, R. L. (1980). A Cognitive Model of the Antecedents and Conseqences of Satisfaction Decisions. Journal of Marketing Research (JMR), 17(4), 460-469.

Parasuraman, A., Zithaml, V., \& Berry, L. (1988). SERVQUAL: A Multiple-Item Scale for Measuring Consumer Perceptions of Service Quality. Journal of Retailing, 64(1), 12-40.

Prameka, A. S., Do, B., \& Rofiq, A. (2016). How Brand Trust is Influenced by Perceived Value and Service Quality: Mediated by Hotel Customer Satisfaction. Asia-Pasific Management and Business Application, 2(2), 72-84. http://doi.org/10.21776/ub.apmba.2016.005.02.2

Riorini, S. V. (2016). Commitment Sebagai Variabel Mediasi Pengaruh Trust Terhadap Repurchase Intention Pada Restoran Waralaba Lokal. Jurnal Manajemen, XX(01), 1-18.

Senić, V., \& Marinković, V. (2013). Patient care, satisfaction and service quality in health care. International Journal of Consumer Studies, 37(3), 312-319. http://doi.org/10.1111/j.14706431.2012.01132.x

Shang, S. (2014). Assessment of E-government Service Quality under User Satisfaction Orientation : The Establishment of E-Govqual Model. Asian Journal of Business Management, 6(2), 111-117.

Susanto, A., Chang, Y., \& Ha, Y. (2016). Determinants of continuance intention to use the smartphone banking services. Industrial Management \& Data Systems, 116(3), 508-525. Retrieved from http://www.scopus.com/inward/record.url?eid=2-s2.0-84962446612\&partnerID=tZOtx3y1

tom Dieck, M. C., Jung, T. H., Kim, W. G., \& Moon, Y. (2017). Hotel guests' social media acceptance in luxury hotels. International Journal of Contemporary Hospitality Management, 29(1), 530-550. http://doi.org/10.1108/IJCHM-10-2015-0552

Wilkins, H., Merrilees, B., \& Herington, C. (2007). Towards an understanding of total service quality in hotels. International Journal of Hospitality Management, 26, 840-853.

http://doi.org/10.1016/j.ijhm.2006.07.006

Wu, H. C., Cheng, C.-C., \& Hong, W. (2017). An assessment of zoo visitors' revisit intentions. Tourism Analysis, 22, 361-375. http://doi.org/10.3727/108354217X14955605216104

Yannopoulou, N., Koronis, E., \& Elliott, R. (2011). Media amplification of a brand crisis and its affect on 
Pengaruh Kualitas Layanan, Kepuasan, Kepercayaan dan ... (Margaretha Pink Berlianto)

brand trust. Journal of Marketing Management, 27(5-6), 530-546.

http://doi.org/10.1080/0267257X.2010.498141

Yusmadi. (2015). Bisnis Salon di Indonesia Sumbang Rp 1 Triliun Per Tahun. Retrieved March 2, 2018, from http://aceh.tribunnews.com/2015/10/07/bisnis-salon-di-indonesia-sumbang-rp-1-triliun-pertahun

Zeglat, D., Shrafat, F., \& Al-smadi, Z. (2016). The Impact of the E-Service Quality of Online Databases on Users 'Behavioral Intentions : A Perspective of Postgraduate Students. International Review of Management and Marketing, 6(1), 1-10. 